\title{
Conceptual Integration Theory in Social Issue Advertisements
}

\author{
Anela Mulahmetović Ibrišimović* \& Nerma Pezerović-Riđić**
}

\begin{abstract}
The aim of this paper is to examine the extent to which conceptual integration theory can be applied to the analysis of social issue advertisements. Taking into consideration that we live in a visually-dominated culture, visual resources such as advertisements, cartoons, and memes have been used in crafting short, eye-catching messages, seeking the biggest impact with a limited amount of space and/or time. In recent years, there has been an enormous interest in the way conceptual integration theory can be used in explaining how the mentioned resources are formed, used, and what messages they can convey. Therefore, this paper is an attempt to examine the applicability of the theory in the study of social issue advertisements.
\end{abstract}

Key words: conceptual integration theory, social issue advertisements, blending, network, verbal, visual

\footnotetext{
* University of Tuzla; aimulahmetovic@gmail.com

** University of Tuzla; nerma_777@yahoo.com
} 


\section{Introduction}

The phenomenon of advertising has permeated every aspect of our society, ranging from our homes to our workplaces. Whether walking down the street, listening to music, or watching television, modern society is surrounded by advertisements. The prime purpose of advertising is not ambiguous since advertisements, both commercial and noncommercial, are exclusively about selling and/or promoting a service, a product, or an idea. Forceville $(2002,65)$ notes that "if this central intention does not come across, an advertisement has failed.”

In order to entice the consumer's purchasing attention, advertisers apply various techniques that vary in their complexity and sophistication. Thus, advertisements tend to be original, unique, and innovative to move away from the drab, uninspiring, and commonplace. A level of artistic creativity within an advertisement depends on the successful combination of primary and secondary substances of language, most notably verbal, auditory, and visual elements (Cook 2001, 27). Even though their conflation often results in an apparent mismatch, an advertiser is careful enough to provide the audience with just enough information to disentangle the composing elements and comprehend the intended message. In doing so, the advertiser exploits the unwritten convention of artistic liberty and audiences' background knowledge triggered by the advertisement resources. Cook $(2001,33)$ observes that advertisements are "parasitic upon their surroundings and other genres [...] they exploit not only the substance and the medium, but also its connotations.”

By applying the framework of conceptual integration theory, this paper aims to explore the interplay of verbal and visual resources in a social issue advertisement. In recent years there has been an avid interest in testing the applicability of conceptual integration theory to a great number of cognitive and linguistic phenomena. A case in point are studies on metaphor (Grady, Oakley, and Coulson 1999), unrealistic scenarios (Coulson and Pascual 2006), cartoons (Bergen 2003, Delibegovic Dzanic and Berberovic 2014), and humour (Coulson 2002, Coulson 2005, Delibegovic Dzanic and Berberovic 2010, Berberovic and Delibegovic Dzanic 2015). By applying conceptual integration theory to the analysis of social issue advertisements, this paper aims at exposing processes that underlie the comprehension of advertisements' messages. It is hypothesised that the meaning of a social issue advertisement emerges through a set-up of a cognitive network model that generates a blend of elements from distinct inputs. 


\section{On Conceptual Integration Theory}

Conceptual integration theory, commonly known as blending, has emerged as an offspring of Fauconnier's mental spaces theory. In one of his works, Fauconnier (1994, xvii) states that meaning construction or conceptualisation is inseparable from the context since sentences serve as cues for the construction of mental spaces. Mental spaces are said to be "structured, incrementable sets, that is, sets with elements [...] and relations holding between them [...] such that new elements can be added to them and new relations established between their elements" (Fauconnier 1985, 16). In other words, mental spaces are temporary containers of information created for the purpose of better comprehension of a spoken or a written discourse. When they are prompted by syntactic elements such as prepositional phrases, adverbs, and conjunctions termed "space builders" by Fauconnier (1994, 17), mental spaces are formed through selective recruitment of the existing stock of knowledge, often in the form of frames or domains ${ }^{1}$, and connected via mappings between counterpart elements. Once the mapping has been established, the speaker can use the element to refer to its counterpart. Grady, Oakley, and Coulson $(1999,101)$ note that mental spaces cannot be equated with domains found in cognitive metaphor theory as the former are smaller in capacity and structured by the latter.

Even though conceptual blending theory is seen as an advancement of mental spaces theory with the aim of clarifying novel inferences (Coulson and Oakley, 2005), Fauconnier and Turner (1994, 16-17) claim that conceptual integration or blending, along with framing, analogy, metaphor, grammar, and common sense reasoning, is a basic cognitive operation, even more basic than metaphor. For the very same reason it often slips by unnoticed on account of its simplicity and speed of processing as "the mind seems to have only feeble abilities to represent itself consciously what the unconscious mind does easily" (Fauconnier and Turner 2002, 18).

Inherent to conceptual integration is the conceptual integration network as a model of how meaning is mentally constructed. The network encompasses minimally four mental spaces that are structured by many different domains, namely two input spaces connected by counterpart matching or cross-mappings that is indicated by solid lines in the diagram, a generic space, and a blended space (Fauconnier and Turner 2002, 47). The link between the generic space and input spaces is bidirectional. The generic space

\footnotetext{
1 Fillmore $(1982,119)$ defines a frame as "a system of categories structured in accordance with some motivating context," while Kövecses $(2002,5)$ describes domain as "any coherent organization of experience”. Even though some authors claim that frames are smaller than domains, Croft and Cruse (2004, 17) suggest that the terms have been used to designate the same theoretical framework and use the two interchangeably. The same stance has been adopted in this paper.
} 
inherits elements from the inputs, creating a less detailed structure than the one found in the input spaces, that is in turn mapped onto its counterparts in the inputs. There is a partial projection from the inputs into the blended space marked by the broken lines in the diagram. What emerges in the blend is a novel structure that remains connected to the inputs, as the blend "contain[s] [a] generic structure captured in the generic space but also contain [s] [a] more specific structure, and it can contain [a] structure that is impossible for the inputs" (ibid). The emergent structure that arises in the blend, and its concomitant relations, are not copied there directly from any input. It is induced in three ways through the processes of composition, completion, and elaboration (ibid). In this respect, composition involves bringing elements from the input spaces into the blend, either separately or by fusion. Completion, in turn, can be defined as "pattern completion that occurs when structure in the blend matches information in long-term memory" (Coulson and Oakely 2000, 180). In other words, completion refers to unconscious recruitment of the background knowledge. The final process or elaboration can be described as running imaginative simulations of the event in the blend.

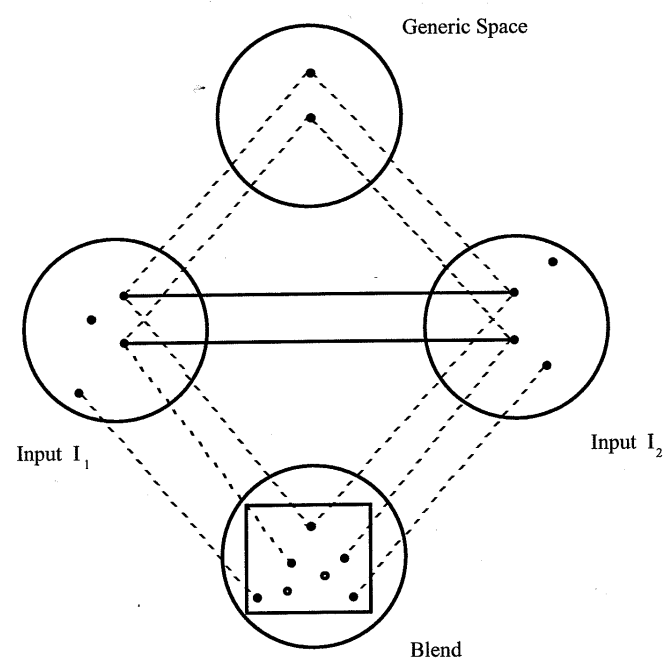

Figure 1: Elements of Blending (Fauconnier and Turner 2002, 46)

Despite being a basic cognitive operation, conceptual blending cannot operate freely in any kind of way. Rather, it is constrained by a set of vital relations and optimality principles pertinent to the formation of the blend ${ }^{2}$. A vital relation is a connector that links the counterparts in the mental spaces and gives rise to the outer-space relations. In the

2 The principles are listed as follows: The Integration principle, The Topology principle, The Web principle, The Unpacking principle, The Good Reason principle, and the Metonymic Tightening principle (Fauconnier and Turner 2002,327f). 
blend, a vital relation can be compressed in order to tighten the counterpart connection and is known as an inner-space relation since it holds inside a single mental space. Fauconnier and Turner $(2002,92-93)$ propose the following array of vital relations:

- Change: a vital relation that connects either individual elements or groups of them. It is closely associated with the Identity vital relation;

- Identity: elements in different mental spaces are connected via the relation of personal identity or a common attribute such as role;

- Time: a link that connects events across mental spaces or involves compression by syncopation;

- Space: bringing elements from different physical spaces into a single physical space;

- Cause-effect: a vital relation that connects a cause element with its effect;

- Part-Whole: rests on a metonymic relation between a part and a whole;

- Representation: relating one element with another that represents it;

- Role: a vital relation that links the role element with the value element;

- Analogy: a vital relation that emerges as a result of the role-value compression;

- Disanalogy: a relation based on analogy and that is often compressed into Change. It enables the mental preservation of the element's identity;

- Property: assigning an attribute to an element;

- Similarity: linking elements with their shared properties;

- Category: a vital relation that hold between a class and its elements on the basis of the possession of particular shared characteristics;

- Intentionality: concerned with whether events and reactions in mental spaces are unintentional or deliberate; and

- Uniqueness: numerous vital relations get compressed into the Uniqueness relation.

The entire system of vital relations and optimality principles provides not only the theoretical foundation for conceptual integration theory, but it also inhibits the allegation of it being too powerful and applicable to almost anything (cf. Gibbs 2000). Yet, what Fauconnier and Turner $(1998,63)$ find remarkable is how blending as a "general-purpose, fundamental, indispensable cognitive operation, routinely employed in a variety of domains, commonly interactive with other cognitive operations [...] should have received so little systematic attention in the study of cognition and language". In this regard, it comes as no surprise that in recent years conceptual integration theory has found its application in the analysis of a number of cognitive and linguistics phenomena including advertising. 


\section{On Advertising}

Cook (2001) points out that the definition of advertising is difficult to pin down, given its complexity and different viewpoints on the subject matter. Yet, along with Forceville $(2002,68)$, he subscribes to the view that the aim of an advertiser is "to persuade a prospective client to buy (literally or figuratively) his/her product, service or an idea". One way of achieving the latter is via social advertising as "the use of advertising to inform the public about the social issue or to influence their behaviour" (Truss, Marshall, and Stevens 2010,24). In other words, advertisements of this kind aim at raising awareness about important social issues and provoking emotional responses on the basis of the advertisement-embedded stimuli. Helde $(2014,169)$ observes that "the concept of social advertising in the context of social marketing is associated with the spread of social advertising, distribution channels, or places where people can see it and understand what specific response, or change of behavior is expected of them".

Considering that advertisers are time-, space-, and budget-constrained, they try to make their advertisement appealing to consumers in order to capture their attention. Creativity as a prerequisite for advertising effectiveness is based on a number of factors, "including the target audience, the basic problem the advertising must address, what the message seeks to accomplish, and the major selling idea or key benefit the advertiser wants to communicate" (Mayer 2005, 80). As a result, advertisement makers pay close attention to the advertising design and craft elements that are unusual and novel in order to enhance advertisements' memorability and pleasantness. Hence, advertisements may incorporate a conspicuous picture, fictions, puns, word play, compressed storytelling, and/or a verbal heading (Cook 2001,3) in order to attract attention and provoke emotions.

Given that visual and verbal rhetoric in advertisements play the role of attentiongrabbing and emotion-eliciting devices, a number of papers have examined their impact upon the audience. McQuarrie and Mick (2003) conducted a study in which subjects were tested on the basis of manipulated direct processing or incidental exposure to advertisements. The study found that the recall of advertisements containing visual and verbal figures was superior to the recall of advertisements without them. McQuarrie and Mick also pointed out that visual figures had an advantage over verbal figures in terms of processing, as the latter produced a better response only if the subjects had processed the advertisements.

Dens, De Palsmacker and Puttemans (2011) investigated the effect of visual and verbal elements on the audience's attitude towards the advertisements for new brands and line extensions. The authors were also interested in the degree of persuasiveness of advertising. In concordance with McQuarrie and Mick's (2003) findings, the study suggested 
that advertisements for a line extension incorporating a pictorial or linguistic element generated a more positive response than advertisements without them. Furthermore, advertisements for a new brand containing incongruent visuals had a negative impact on the brand image, while providing only verbal information for a brand had the same effect as providing no information at all. Dens, De Palsmacker and Puttemans (2011, 353) concluded that for a line extension "the best combination would be to rely on dual coding and provide both a visual (product related or not) with at least a basic amount of information. In new brand campaigns, providing too much information and especially nonproduct related visuals should be avoided".

Van Enschot, Hoeken and Van Mulken (2008) analysed the audience's attitude towards verbo-pictorial rhetorical figures. The authors made a distinction between a verbopictorial scheme as a minor, superficial deviation in the connection between a text and an image, and a verbo-pictorial trope "as a seeming mismatch between the headline and the picture in an ad" (Van Enschot, Hoeken and Van Mulken 2008, 37). The study revealed that verbo-pictorial schemes garnered a more positive response than verbo-pictorial tropes, as advertisements with the latter were perceived as less complex and thus easier to interpret.

In addition, some of the cognitive linguistics literature focused on the role of blending in the conflation of visual and verbal resources in advertisements. Herrero Ruiz (2006) explored the significance of metaphor, metonymy, and conceptual blending in understanding drug-prevention advertisements. He proved that these cognitive tools anchored the viewers toward the correct interpretation of the advertisements' central messages. Lundmark (2003) expressed her interest in the connection between metaphor, metonymy, blending, and humour in relation to puns in print advertisements. Lundmark $(2003,29)$ noted that "the extent to which different people find different puns and advertisements funny can vary considerably, since the degree of blending often depends on what the reader does with the minimal clues that are provided in the text and the picture(s) of the advertisement”. In a similar vein, Delibegovic Dzanic and Berberovic (2012) examined how conceptual blending can be applied in the analysis of text-image advertisements, while Joy et al (2008) inspected the occurrence of metaphor and blending in simple, mirror, and single-scope networks in advertisements. Taking all this into consideration, it stands to reason to hypothesise that conceptual integration theory can account for the construction of meaning in social issue advertisements, as well as the comprehension of the ideas behind them. The validity of the hypothesis is going to be tested by analysing three such advertisements within the framework of conceptual integration theory. 


\section{Conceptual Integration Theory in Social Advertisements: A Case Study}

The occurrence of blending in advertisements is said to be twofold (Lundmark 2003, 10). First, it allows advertisers to evoke positive feelings with an advertised product. Second, blending is said to be underspecified as input projections can occur in different ways and the interpretation of the emergent structure, although fixed to a great extent, is contingent on the target audience. In the examples analysed in this paper, the blend is not concerned with generating a positive affective response. Instead, it capitalises on provoking the audience's emotional reactions and exploits them as catalysts in the promotion and acceptance of the advertising theme.

The first social issue advertisement to be analysed is taken from a 2010 campaign against racism and anti-Semitism by the French LICRA (Ligue Internationale Contre le Racisme et l'Antisémitism). As France has been a leading progressive country on social issues concerning race and politics, advocates have addressed racial issues by excluding ethnic features from the national census. Consequently, minorities are not recognised by their ethnic or racial features as per Article 1 of the French Constitution. The LICRA campaign with the slogan "Your Skin Color Shouldn't Dictate Your Future" was aimed at raising awareness of the issues of racial identity in French society.

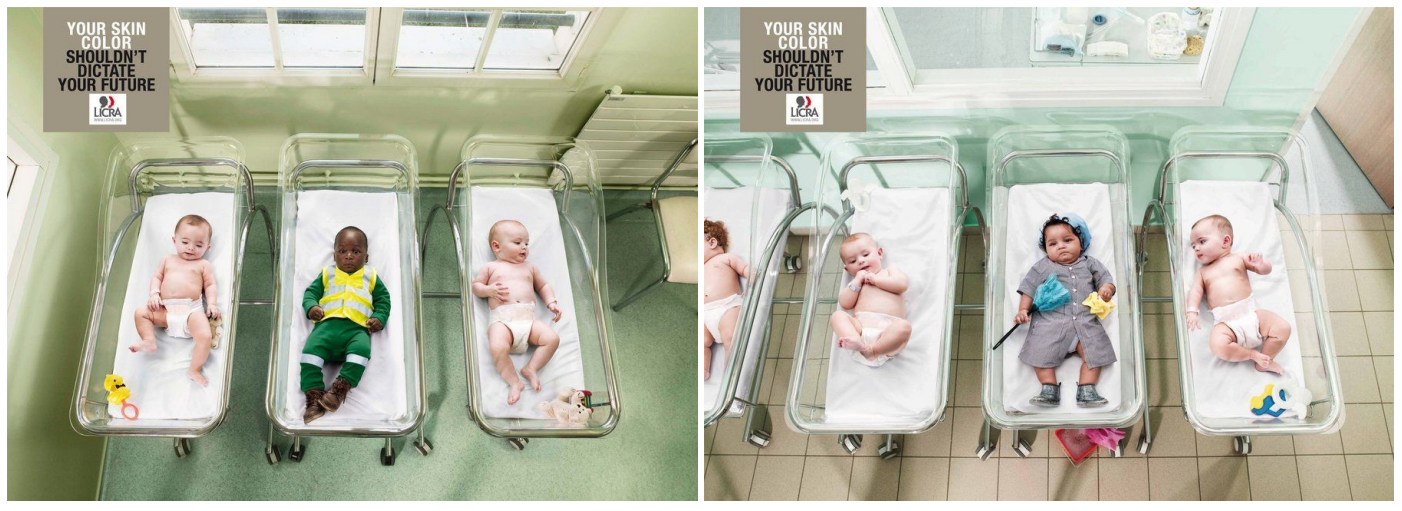

Figure 2: Source: http://www.ufunk.net/en/publicite/contre-le-racisme-et-lantisemitisme/

The integration network is a single-scope network consisting of four spaces, two input spaces, a generic space, and a blended space. Input space one comprises a nursery for new-borns with several babies in their cribs. The image of the babies implies racial identities. Ideally, all patients should be treated equally and receive the best medical care. Input space two contains the concept of racism in France. It emphasises racial discrimination against people of colour. The cross-space mappings are established between the babies in the input space one and the black and the white population in input space 
two. The generic space captures the structure that is common to the two inputs, that is, different ways of treating people. The fourth mental space or the blended space contains projections from the two inputs. Projected from input space one are the organizing frame, as well as the babies and the cribs. Projected to the blend from input space two are racial discrimination against blacks and white supremacy in French society. In the blend, black babies in a nursery wear uniforms that symbolise lower-paid and lower-status jobs, as opposed to white babies whose future has not been stigmatised. The portrayal of racial discrimination is further strengthened by the presence of toys in the white babies' cribs and their absence in their black counterparts. The blend exploits several vital relations, some of which are to be run mentally, such as Identity, Time, and Change (it takes time for babies to grow into adult humans, but still keep their identity), Cause-Effect (one of the effects of a racial discrimination is the limited access to educational resources resulting in lower-paid jobs), Part-Whole (babies' clothing standing for workers' uniforms), Analogy, Disanalogy, Representation, and Category (white and black babies represent the entire racial group, while at the same time they preserve their individual identity), and Uniqueness (every blend has a unique structure). In addition, the blend provides backward projections to the input spaces, suggesting that skin colour should not be the basis of unequal treatment. It is suggested that reality contradicts the much-advocated image of the ideal in French society.

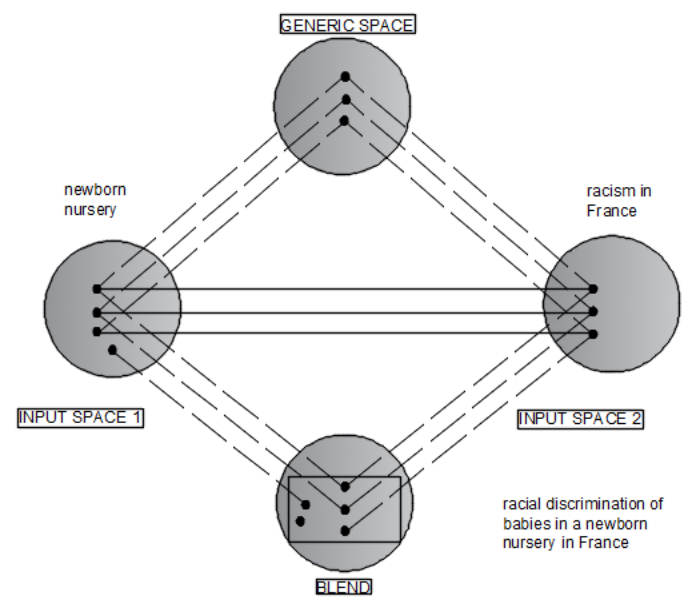

Figure 3: Conceptual integration network for the "Your Skin Color Shouldn't Dictate Your Future" social issue advertisement

The next social issue advertisement is part of the 2014 "Liking is not helping. Be a volunteer. Change a life" campaign developed by Publicis Singapore for Crisis Relief Singapore. Three images utilised in this campaign reflect three types of catastrophes: floods, earthquakes, and war. Awarded with a First Prize Award at the New York Festivals and 
a Golden Lion at the Cannes Festival, the campaign plays on the idea of virtual empathy not being equal to real-life support. In this paper, only the image depicting war victims was selected for analysis, even though the same slogan appeared in all three.

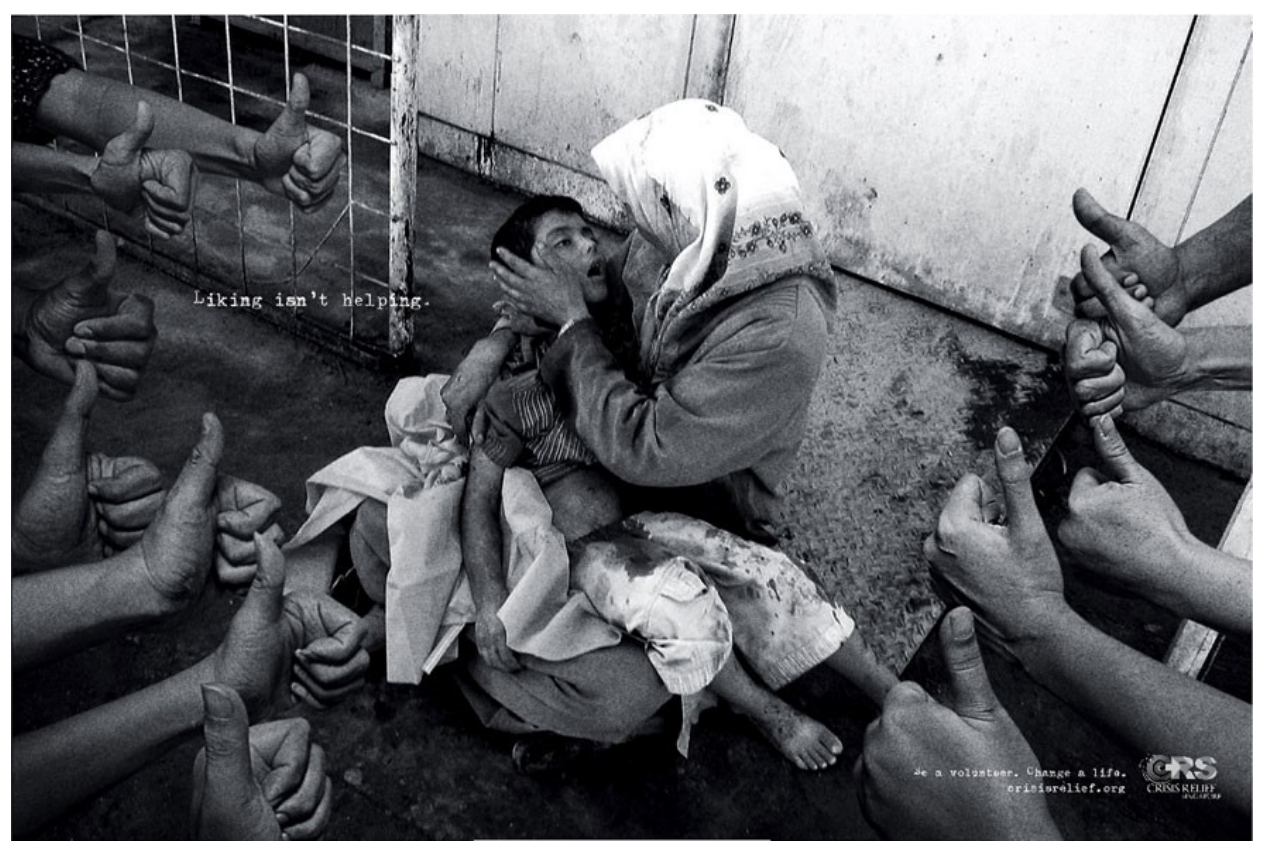

Figure 4: Source: https://digitalsynopsis.com/inspiration/60-public-serviceannouncements-social-issue-ads/

In this four-space conceptual integration network, input space one contains the domain of war structured by our knowledge of the concept. Therefore, it encompasses the notion of aggression, conflict, destruction, weapon, casualties, war victims, humanitarian aid, rescue workers, and different kinds of volunteers and their services. Input space two contains Facebook, a free social networking site that offers a variety of communication methods. The most popular Facebook feature is the "Like" button designed as a hand

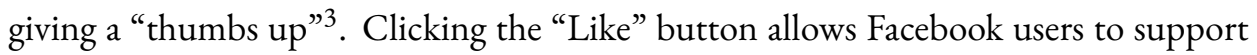
certain content or to take part in a variety of virtual humanitarian aid activities, such as feeding children in Africa or raising money for those in need. Cross space-mappings connect the volunteers and their work from input space one with Facebook users and the act of clicking the "Like" button from input space two.

The generic space contains skeletal information from the two inputs - persons providing services for no financial gain. The blended space involves selective projections

\footnotetext{
3 As of February 2016, Facebook has changed its "Like" button to include a range of emotions termed as Like, Love, Haha, Wow, Sad and Angry emojis (Titcomb, 2016).
} 
from the input spaces. Projected to the blend from input space one are the organising frame of war, volunteer aid workers, and their work. The process of compression of group identity into particular identity takes place, thus war victims are compressed over time and space into a mother and son. Following compression, the mother and son are projected to the blend. The horrors of war are accentuated by the blood on the boy's trousers and the mother holding him in her arms, while the audience is left to speculate on his health condition. Projected from input space two are Facebook users clicking the "Like" button. The blending process fuses the volunteer aid workers and their activities with Facebook users and the act of clicking. As a result, Facebook users is the element brought into the blend, but their activity is restricted to a thumb signal, metonymically standing for the Facebook "Like" button.

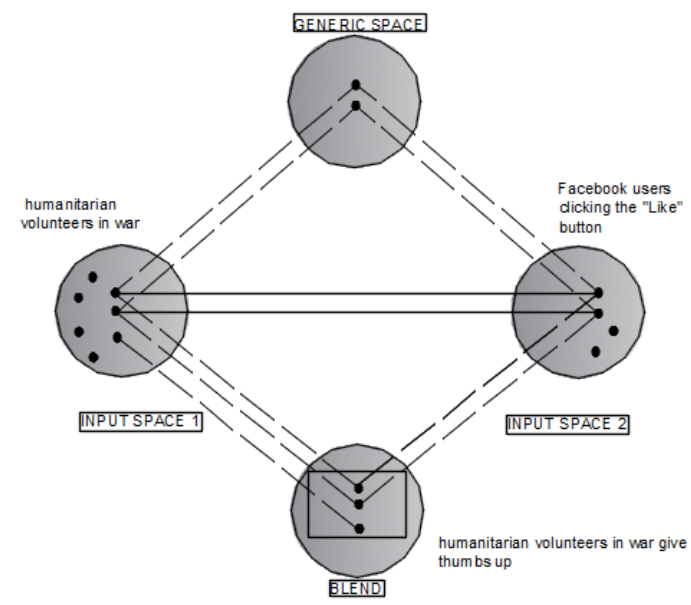

Figure 5: The conceptual integration network for the "Liking is not helping. Be a volunteer. Change a life" social issue advertisement

The blend largely depends on several vital relations, namely Space (the mother and son and volunteers share the same physical space), Part-Whole (hands giving thumbs up stand for people), Analogy, Disanalogy, Representation, and Category (mother and son represent the category of victims, while, at the same time, they preserve their individual identity), Intentionality (volunteers deliberately give thumbs up in the blend) and Uniqueness. Furthermore, the blend itself represents an incongruity that needs to be accounted for. Therefore, unpacking of the blend enables the backward projection and reconstruction of the input spaces. In that sense, the audience is led to infer that virtual support in the form of clicking the "Like" button will not relieve the pain of those suffering. The textual part "Liking isn't helping” aims to dispel this widespread misconception and stresses the importance of an individual's action. 
The third social issue advertisement tries to bring attention to the issues of gender inequality and women's rights. The campaign consists of a series of advertisements created by Memac Ogilvy \& Mather Dubai for the UN, inspired by the actual March 9, 2013 Google searches that revealed the prevalence of sexist attitudes. On their website, UN women (2013) state that the intent of the campaign was to "expose negative sentiments ranging from stereotyping as well as outright denial of women's rights”. Historically a hot topic, the issue of women's rights provides an important framework for the interpretation of the advertisement.
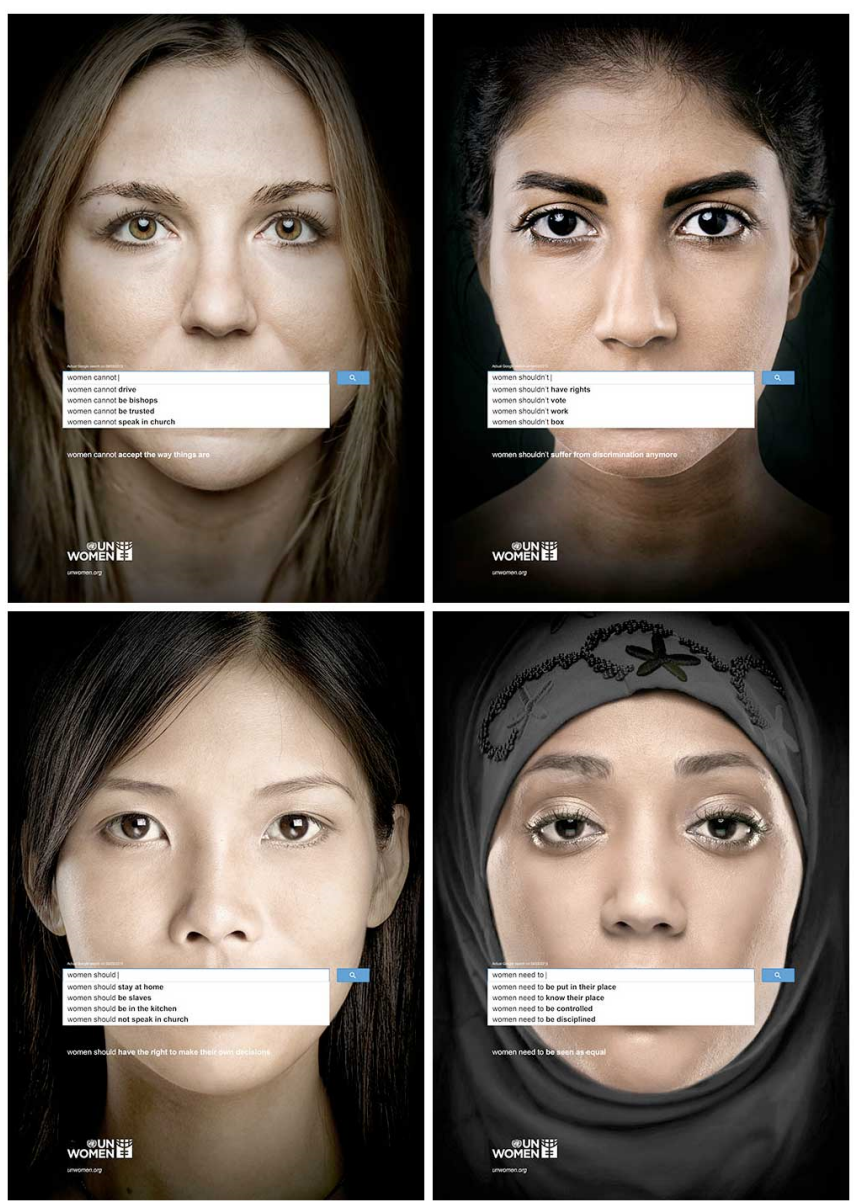

Figure 6: Source:

http://www.unwomen.org/en/news/stories/2013/10/women-should-ads

The conceptual integration network is composed of three input spaces, a generic space, and a blended space. Input space one contains women around the world that vary in race, nation, and ethnicity. Input space one also contains the concept of women's rights. According to United Nations Human Rights (2017), women are often deprived of their health rights and rights to equal access to land, property, and housing. Input space two 
space utilises Google's search engine and a list of the most searched phrases on women suggested by the Google autocomplete search function. The Google queries "women cannot", "women should", "women need to" and "women shouldn't," were autocompleted with "women need to be put in their places," "women cannot be trusted," "women shouldn't have rights," and "women should stay home” results. It needs to be highlighted that this autocompletion is based on real Google searches by users worldwide. Finally, input space three comprises the notion of restraint that is metonymically symbolised by the duct tape.

Cross-space mappings are established between women in input space one and the searched phrases on women in input space two. The element of women, along with the act of restraining, forms the structure of the generic space. Consequently, the generic space is comprised of women that are silenced with duct tape over their mouths.

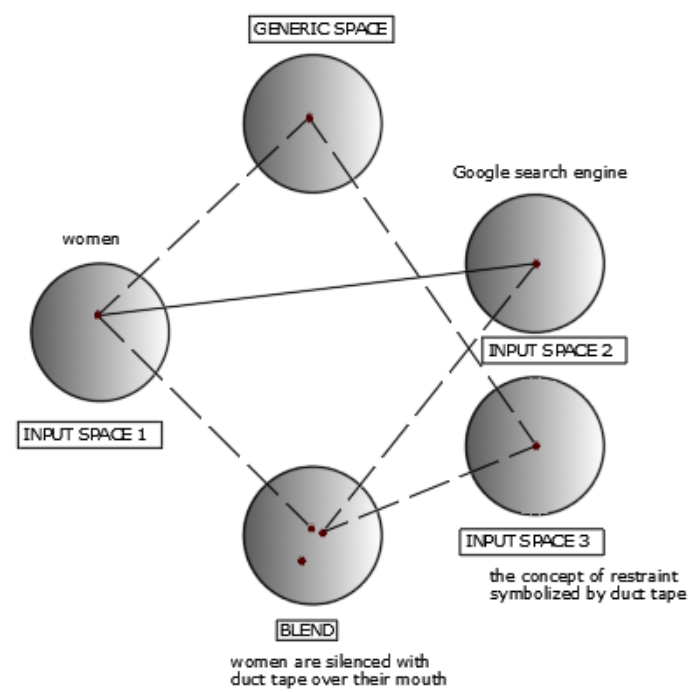

Figure 7: The conceptual integration network for the "Women should" social issue advertisement

The blended space contains selective projections from the three inputs. Women in input space one are compressed over time and space by homogenising their appearance, experience, and behaviour into a prototypical representative, based on commonly shared characteristics. In this regard, the blend exploits Part-Whole, Category, Representation, Analogy, Disanalogy, and Identity vital relations by projecting a Caucasian, an Asian, an Arab, and an Indian woman from input space one. The search phrases are brought from the second input space, while the duct tape is projected from the third input space. As a result, the blend contains four women with the duct tape over their mouths that has been merged with the list. In the blend, women are unable to voice their opinion but have sexist attitudes imposed on them. 
In addition, the unpacking of the blend demands the backward projection and reconstruction of the input spaces. The projection spotlights women regularly suffering violations of their rights. The blend recognises the obligation of every state to eliminate discrimination against women and the infringement of their rights. Consequently, the improvement of women's status will be reflected in various areas of social discourse, including Internet search.

\section{The Creation of Meaning in Social Advertising via Conceptual Blending}

It has been demonstrated that the creation of meaning in a social issue advertisement can be explained by applying conceptual integration theory. While processing an advertisement, a conceptual network is built by partitioning information into input spaces that give life to the abstractions of the generic space. After establishing the cross-space mappings between the mental spaces, a blended space with the bits of information from different inputs relevant for the advertisement comprehension is set up in the brain. Taking into consideration that social issue advertisements have the aim of drawing attention to issues of public interest, advertisement makers use emotive elements such as a striking picture, an unusual heading, or a trope to achieve their aim. Delibegovic Dzanic and Berberovic $(2012,558)$ claim that the interaction of different elements in an advertisement makes it "an interpretative puzzle" that needs to be solved by taking into account the pictorial element and the linguistic material portrayed in the picture as the latter has the purpose of constraining possible interpretations and guiding the viewer to the intended one. The examples analysed in this paper are no different. Thus, in the first example, the emergent structure implies that the central message behind the advertisement is the provision of tougher support against racial discrimination and segregation. In the second advertisement, the blend highlights the fact that posting a courageous status/photo and getting thousands of virtual likes will be rendered ineffective unless users take prompt action. The blend also ridicules the idea of virtuality being treated as a substitute of reality, rather than as its supplement. The third example highlights that the concept of women's rights is still met with resistance around the world, contravening equality with men.

Conversely, it has been stated that blending is underspecified in the sense that the emergent structure can be applied to different contexts. Therefore, in our first case study, the unequal treatment motivated by skin colour in French society is analogous to discrimination based on race, religion, or national origin worldwide. In the second 
example, ramifications of trauma suffered in war and the social media users' passivity are reminiscent of the public disinterest that generally follows conflicts around the globe. In the third advertisement, a small portion of rights-deprived women depicted in the image has the purpose of making the public recognise the gravity of the problem, treat it with seriousness, and spur people to action. As Forceville $(2002,72)$ concludes, it is nearly impossible to observe a depicted object - including advertisements - and be aware of its denoted meaning without paying attention to its possible connotations.

\section{Conclusion}

This paper presents an analysis of social issue advertisements within the framework of conceptual integration theory. The main goal of the paper was to shed light on the construction of meaning in social issue advertisements, as well as the comprehension of central ideas behind them. It was hypothesised that visual and verbal resources have a key role in the creation of advertisements' meanings. Conceptual integration theory seemed a suitable tool for the analysis of advertisements since it allowed for complex cognitive phenomena to be broken down into a series of smaller events. In all three analysed examples, conceptual integration network was established by cobbling mental spaces together and creating the blend, with the help of visual and verbal elements contained in the advertisement. The blend as such represented an incongruity that needed to be solved. What followed was the unpacking of the blend and the reconstructing of the input spaces. The reconstruction was performed by relying on visual and verbal elements that pointed the viewers in the right direction. Following the reconstruction, the backward projection to the input spaces highlighted the contrast between the emergent structure in the blend and the elements in the inputs and, as Delibegovic Dzanic and Berberovic $(2010,210)$ noticed, "reinforce[d] construals in input spaces in accordance with the new structure created in the blend". In this way, viewers were able to grasp the main idea behind the advertisement.

Taking everything into account, it can be concluded that conceptual integration theory can be applied to the analysis of advertisements. The paper confirmed the hypothesis by showing that visual and verbal resources are exploited in an advertisement in order to grab attention, aid the creation of meaning, and incite people to act. It can be suggested that the appeal of conceptual integration theory is the explanatory power of how human beings think. 


\section{References}

Berberović, Sanja, and Nihada Delibegović Džanić. 2015. "Bitno je biti...? - Teorija konceptualne integracije i internetski politički memovi.” Dimenzije značenja, 9-30.

Bergen, Benjamin. 2004. “To Awaken a Sleeping Giant: Blending and Metaphor in Editorial Cartoons after September 11.” In Language, Culture, and Mind, edited by Michel Achard and Suzanne Kemmer, 23-35. Stanford: CSLI Publications.

Bleich, Eric. 2001. Race Policy in France. Cambridge: Cambridge University Press. Accessed 12 September 2019. https://www.brookings.edu/articles/race-policy-in-france/.

Cook, Guy. 2001. The Discourse of Advertising. London: Routledge.

Coulson, Seana, and Todd, Oakley. 2001. "Blending Basics." Cognitive Linguistics 11, no. 3-4: 175-196. Accessed 12 September 2019. https://doi.org/10.1515/cogl.2001.014.

Coulson, Seana. 2001. "What's so funny: Conceptual Blending in Humorous Examples." In The Poetics of Cognition: Studies of Cognitive Linguistics and the Verbal Arts, edited by Vimala Herman. Cambridge: Cambridge University Press.

Coulson, Seana. 2005. "Extemporaneous Blending: Conceptual Integration in Humorous Discourse From Talk Radio.” Style 39, no. 2: 107-122.

Coulson, Seana, and Tod Oakley. 2005. "Blending and Coded Meaning: Literal and Figurative Meanings in Cognitive Semantics.” Journal of Pragmatics 37: 1510-1536. Accessed 12 September 2019. https://doi.org/10.1016/j.pragma.2004.09.010.

Coulson, Seana, and Esther Pascual. 2006. "For the Sake of Argument: Mourning the Unborn and Reviving the Dead Through Conceptual Blending.” Annual Review of Cognitive Linguistics 4: 153-181. Accessed 12 September 2019. https://doi.org/10.1075/arcl.4.07cou

Croft, William and D. Alan Cruse. 2004. Cognitive Linguistics. Cambridge: Cambridge University Press.

Delibegović Džanić, Nihada, and Sanja Berberović. 2010. “On Politicians in Big Women’s Sunglasses Driving Buses with their Feet in Mouths: Late-Night Political Humour and Conceptual Integration Theory.” Jezikoslovlje 11, no. 2: 197-214.

Delibegović Džanić, Nihada, and Sanja Berberović. 2012. “Conceptual Integration Theory in Text-Image Advertisements.” In Contemporary Foreign Language Education: Linking Theory into Practice, edited by Azamat Akbarov and Vivian Cook, 559-569. Sarajevo: IBU.

Delibegović Džanić, Nihada, and Sanja Berberović. 2014. "Hot Cakes: The Use of Idioms in Political Cartoons.” In Phraseology and Culture, edited by Vida Jesenšek and Dmitrij Dobrovol'skij, 339-353. Bielsko-Biala - Budapest - Kansas - Maribor - Praha: Zora.

Dens, Nathalie, Patrick De Pelsmacker, and Bianca Puttemans. 2011. "Text or Pictures? Effectiveness of Verbal Information and Visual Cues in Advertisements for New Brands versus Extensions.” In Advances in Advertising Research (2), edited by Shintaro Okazaki, 341-355. Wiesbaden: Gabler Verlag.

Fauconnier, Gilles. 1985. 1985. Mental Spaces. Cambridge, Mass.: MIT Press.

Fauconnier, Gilles, and Mark Turner. 1994. “Conceptual Projection and Middle Spaces.” Cognitive Science Report 9401. 
Fauconnier, Gilles.1994. Mental Spaces: Aspects of Meaning Construction in Natural Language. Cambridge: Cambridge University Press.

Fauconnier, Gilles, and Mark Turner. 1998. "Conceptual Integration Networks." Cognitive Science 22, no. 2: 133-187.

Fauconnier, Gilles, and Mark Turner. 2002. The Way We Think: Conceptual Blending and the Mind's Hidden Complexities. New York: Basic Books.

Fauconnier, Gilles. 2007. "Mental Spaces." In The Oxford Handbook of Cognitive Linguistics, edited by Dirk Geeraerts and Hubert Cuyckens, 351-376. Oxford: Oxford University Press.

Fillmore, Charles. J. 1982. "Frame Semantics." In Linguistics in the Morning Calm, edited by Linguistic Society of Korea. 111-137. Seoul: Hanshin Publishing Co.

Forceville, Charles. 2002. Pictorial Metaphor in Advertising. London and New York: Routledge.

Gibbs, Jr., Raymond W. 2000. "Making Good Psychology Out of Blending Theory." Cognitive Linguistics 11: 347-358.

Grady, Joseph, Todd Oakley, and Seanna Coulson. 1999 "Conceptual Blending and Metaphor.” In Metaphor in Cognitive Linguistics, edited by Raymond Gibbs, 101-124. Amsterdam and Philadelphia: John Benjamins.

Helde, Aivars Gabriel. 2014. "Social Advertising.” PhD diss., Department of Communication, Riga International School of Economics and Business Administration.

Herrero Ruiz, Javier. 2006. "The Role of Metaphor, Metonymy, and Conceptual Blending in Understanding Advertisements: The Case of Drug-Prevention Ads." Revista Alicantina.

de Estudios Ingleses 19: 169-190. Accessed 12 September 2019. http://hdl.handle.net/10045/5175. Joy, Annamma, John Sherry, and Jonathan Deschenes. 2009. "Conceptual Blending in Advertising.” Journal of Business Research 62: 39-49. Accessed 12 September 2019. https://doi.org/ 10.1016/j.jbusres.2007.11.015.

Kövecses, Zoltan. 2002. Metaphor: A Practical Introduction. New York: Oxford University Press.

Lundmark, Carita. 2003. Puns and Blending: The Case of Print Advertisements. Accessed 12 September 2019. http://wwwling.arts.kuleuven.ac.be/iclc/Papers/Lundmark.pdf.

McQuarrie, Edward F., and David Glenn Mick. 2003. "Visual and Verbal Rhetorical Figures Under Directed Processing Versus Incidental Exposure to Advertising." Journal of Consumer Research: 1-32. Accessed 12 September 2019. https://doi.org/10.1086/346252

Open Society Institute. 2009. Profiling Minorities: A Study of Stop-and-Search Practices in Paris. New York.

Rosen, Larry D. 2012. "Power of Like: We Like Being Liked...On Facebook.” Psychology Today, July 15. Accessed 12 September 2019. https://www.psychologytoday.com/blog/rewired-thepsychology technology/201207/the-power.

Truss, Aiden, Robert Marshall, and Clive Blair-Stevens. 2010. "A History of Social Marketing." In Social Marketing and Public Health: Theory and practice, edited by Jeff French, Clive BlairStevens, Dominic McVey and Rowena Merrit, 19-28. Oxford: Oxford University Press. 
Titcomb, James. 2016. "Facebook Has Changed the 'Like' Button to Six Different Emotions." The Telegraph, 24 February 2016. Accessed 12 September 2019. https://www.telegraph.co.uk/ technology/2016/02/24/facebook-has-changed-the-like-button-to-six-different-emotions/.

United Nations Human Rights: Office of the High Commissioner. 2017. "Women's Human Rights and Gender Equality.” Accessed 1 May 2017. http://www.ohchr.org/EN/Issues/Women/ WRGS/Pages/WRGSIndex.aspx.

UN Women. "UN Women Ad Series Reveals Widespread Sexism." Accessed 1 May 2017. http://www.unwomen.org/en/news/stories/2013/10/women-should-ads.

Van Enschot, Renske, Hans Hoeken, and Margot van Mulken. 2008. "Rhetoric in Advertising: Attitudes Towards Verbo-Pictorial Rhetorical Figures." Information Design Journal 16, no. 1: 35-45. 